\title{
Some grammatical rules are more difficult than others: The case of the generic interpretation of the masculine
}

\author{
Pascal Gygax \\ University of Fribourg, Switzerland
}

Ute Gabriel

Norwegian University of Science and Technology, Trondheim, Norway

Oriane Sarrasin

University of Bern, Switzerland

Jane Oakhill

Alan Garnham

University of Sussex, Great Britain

In this paper we argue that the generic use of the masculine represents a grammatical rule that might be easy to learn but difficult to apply when understanding texts. This argument is substantiated by reviewing the relevant literature as well as the recent work conducted by the GREL Group (Gender Representation in Language) on the interaction between stereotypical and grammatical information in the construction of a representation of gender when reading role names. The studies presented in this paper show that the masculine form used as a generic to refer to persons of both sexes, or to persons of indefinite sex or whose sex is irrelevant, in gender marked languages is likely to be associated with its specific meaning (i.e., masculine refers only to men). This is true even though the generic nature of the masculine is a very common grammatical rule learnt at school. People may have learned this rule and may understand it, but may not readily apply it.

In gender marked languages such as German or French, the gender of a noun referring to a person is often explicitly signalled by the form of the determiner and by the morphological form of the noun. But the situation is not always clear, because in German as well as in French, for

Most research presented in this paper was supported by research grants from the Swiss National Foundation to Ute Gabriel and Pascal Gygax. 
example, there are specific grammatical rules about the use of masculine and feminine forms: To refer to a group of people of both sexes, to persons of unknown sex, or where the sex of the person is irrelevant, the masculine form is used and is supposed to be interpreted as a generic. Although some pronouns (i.e., he and she) are gender specific, for nouns in general, English can be considered as gender unmarked. Some gender marked nouns do exist in English (e.g., policewoman, chairman), and some studies of the interpretation of those nouns will be presented later (e.g., Liben, Bigler, \& Krogh, 2002), but they are rather uncommon. For this reason, in the remaining of this paper we will consider English as a non-gender-marked language. This is especially important in the current context, as some research presented in this paper has made use of this latter language property (i.e., gender unmarked nouns) and has contrasted languages with different grammatical systems and with different cultural contexts.

Importantly, even though the generic nature of the masculine is explicit in French grammars, such as in Grévisse and Goose (1993) (the term neutral is used), its acquisition by children inevitably follows the revelation that there are grammatically masculine and feminine words. In the French-speaking part of Switzerland, for example, at the age of approximately seven to eight years, children learn that there are two grammatical genders, masculine and feminine, which are arbitrary for inanimate beings, but which are usually non-arbitrary for animate beings. To illustrate this last point, the official handbook for 2nd grade primary school children (i.e., 7- to 8-year-olds) in the French-speaking part of Switzerland gives, for the female examples: la femme [the woman], l'actrice [the actress], la chatte [the female cat]; and for the male examples: le directeur [the director], le marin [the sailor], le boeuf [the beef] ${ }^{1}$. In essence, children first learn that when referring to men, the masculine is usually used, whereas when referring to women, the feminine form is (of course, the few cases, such as la sentinelle [the male guard], when this is not true are also introduced). Between 10-11 years, children learn that adjectives have to be in the masculine plural form when the preceding nouns are either in the masculine form only or in the masculine and feminine forms. Only then are they "properly" introduced to the generic nature of the masculine ${ }^{2}$ (see Figure 1 for an example).

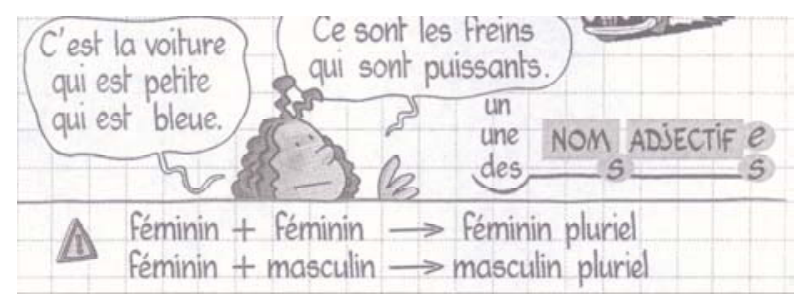

Figure 1. Example of the way children are introduced to the generic nature of the masculine, from Guion and Guion (2000). The girl in the picture shows how to conjugate the adjectives (i.e., in the feminine form when the noun is in the feminine form, and in masculine plural when the noun is in the masculine plural form). However, the sign of caution stresses the rule by which an adjective in the plural form is only in the feminine form when both nouns are in the feminine form. The appearance of one masculine noun forces the adjective to be masculine as well (i.e., interpreted as a generic form)

Proponents of feminist linguistics, however, doubt that the masculine form can be used in a way that abstracts from the gender of its referents (i.e., in a generic way) and claim that the ambiguity about whether a word is used as a generic or not is usually resolved to women's disadvantage: The use of the masculine evokes concepts of men, thus eliminating women as referents (e.g., Braun, 1996; Bussmann, 1995; Peyer \& Wyss, 1998). Proponents of feminist linguistics therefore suggest that the grammatical rule of generic interpretation is not readily applied, or at least is not applied when it should be. Most empirical research on the use of the masculine intended as generic in German (for a review: Stahlberg, Braun, Irmen, \& Sczesny, 
2007) and French (e.g., Colé \& Segui, 1994) seems to support this view, and the present paper provides an overview of the different issues surrounding the matter.

Central to most of these issues is the grammatical complexity accompanying the interpretation of the masculine form. More specifically, in gender-marked languages, such as French, the masculine form can (a) be an arbitrary category, (b) specifically refer to male animate beings, or (c) be interpreted as a generic form (i.e., referring to both male and female animate beings). Children have to learn and master these different interpretations and apply them when reading texts, more specifically when forming a mental representation of gender. Our aim in this paper is to demonstrate that a specific interpretation of the masculine form is dominant when constructing a mental representation of gender through role names, even when it is not intended, not only for children, but also for university students. Children may need more time to fully integrate these rules and apply them, but university students should not, supposedly, show any difficulty in switching interpretations. The paper also addresses the impact that stereotypes and social representations can have on the mental representation of gender and its interaction with grammatical features.

\section{The masculine intended as generic and its interpretation by children}

Flaherty (2001) investigated the influence of grammatical gender on the way children perceive the world by investigating Spanish, a gender-marked language, and English, a nongender-marked language. In one of her experiments, she asked native-English-speaking and native-Spanish-speaking participants of different ages (5- to 7-year-olds, 8- to 10-year-olds and adults) to assign gender and to put typical male or female names to different objects presented in cartoons. Older Spanish participants (8- to 10-year-olds and adults) were inclined to assign gender and names according to grammatical gender, whereas older English participants assigned gender according to specific perceived gender attributes. Both 5- to 7-year-old English and Spanish participants assigned gender according to their own sex more than older participants. In a follow-up experiment, older (8- to 10-year-olds and adult) English and Spanish participants had to assign female and male attributes to animate and inanimate objects. English participants assigned attributes in the same way as they assigned gender in the previous experiment, and Spanish participants' responses were strongly influenced by the grammatical gender of the nouns. Flaherty's (2001) main conclusion was that grammatical gender enabled Spanish participants to assign gender and gender attributes. However, this was the case mainly for older participants (8-year-olds and above) as, according to Flaherty, younger participants (5- to 7-year-olds) had not yet fully acquired the principles of grammatical gender. Most importantly, Flaherty (2001) showed that grammatical gender was not considered as arbitrary, or neutral, by younger children using a grammatically gender-marked language.

In the same vein, Chatard, Guimond, and Martinot (2005) investigated whether the masculine in French was considered as an arbitrary categorisation by youngsters aged fourteen to fifteen. Chatard et al. (2005) assessed the impact of the masculine-only form and alternatives to it (i.e., often referred to as gender-fair language forms) on motivation, confidence and self-efficacy judgements about their own ability to undertake studies that would lead to various jobs. The children were presented with job descriptions, either written only in the masculine form, or written in a gender-fair form. Generally, the participants were more confident when the jobs described were stereotypical of their own gender. However, both girls and boys felt more self-efficacy when the jobs were presented in a gender-fair form [e.g., mécanicien/mécanicienne or mécanicien(ne) $]^{3}$. Chatard et al. (2005) therefore demonstrated that language had an effect on children's representation of jobs and that the masculine form was detrimental to both girls' and boys' confidence in attaining those jobs. Moreover, Chatard et al. also demonstrated a strong stereotypical effect in the lack of confidence of both sex groups to undertake studies leading to jobs stereotypical of the other sex group.

Liben et al. (2002) found a similar pattern when they investigated children's interpretations of English occupational titles. In Liben et al.'s (2002) first study, children of different ages 
were presented with gender marked (e.g., policeman or postmaster) and unmarked (e.g., doctor or librarian) occupational titles and were simply asked whether they thought that the job titles could be applied to both men and women. The occupational titles were also divided into three stereotypical categories (i.e., female, male and neutral). Generally, results showed that responses depended on gender marking (marked occupational titles were less likely to be interpreted as applicable to both men and women), and on gender stereotypes (gender-neutral occupations were more likely to be interpreted as applicable to both men and women). Interestingly, however, Liben et al. (2002) also demonstrated that gender-neutral titles were not always considered as universally applicable to both men and women, and whether they were depended on whether the children held strong stereotypical attitudes.

As for the effect of grammatical marking, one could argue that the seemingly non-existent generic interpretation of the masculine by children is mainly a problem of comprehension. Children have simply not properly understood the rule stating that the masculine form can be interpreted as a generic form. Hyde (1984) found, for example, that although elementary school children (American English users) had learned to produce "his" in a singular gender-neutral context, most of her participants could not articulate why they would do so. However, although explicit knowledge of the rule seemed to increase with age, with only $28 \%$ for first graders (i.e., approx. 6- to 8- year olds) knowing the rule, $32 \%$ for third graders (i.e., approx. 8- to 10 - year olds), $42 \%$ for fifth graders (i.e., approx. 10 - to 12 - year olds) and $84 \%$ for college students (e.g., 18- to 22- year olds), the pronoun "his" was rarely considered as gender neutral by any of the groups. When asked to write a story about a character who was introduced using the pronoun "he" (or "his") in the description (e.g., When a kid goes to school, he often feels excited on the first day), supposedly interpretable as a generic form, only $21 \%$ of the stories written by college students were about a female character (a true generic interpretation would lead to $50 \%$ of the stories written about a female character). Taking the other groups together, only $7 \%$ of elementary school children's stories were about a female character.

Pronominal grammatical gender and gender-marked occupational roles have been investigated in English. Because English is mainly a non-gender marked language, it is not so surprising that the generic nature of the masculine form is not readily appreciated. Some have argued that this aspect of English usage is a direct consequence of different rules and recommendations against on the use of sexist language by governments of English-speaking countries (Markowitz, 1984). In gender-marked languages, such as French and German, the picture is different.

\section{The masculine intended as generic and its interpretation by students}

Gygax, Gabriel, Sarrasin, Garnham, and Oakhill (2008) investigated the extent to which university students would interpret the masculine form as generic in French and German. They focused more generally on role names, which can be defined as names that incorporate features used to describe a person or a group of people, such as occupations (e.g., dentists, actors or students), and hobbies (e.g., soccer fan). Admittedly, as use of the masculine is still very much prominent in French and German (i.e., contrary to English), university students should have fully learned the grammatical rule by which the masculine is generically interpreted and should readily apply it when reading texts. When reading role names in the masculine form, they should readily construct a mental representation that is potentially open to both men and women. Of course, role names are particularly prone to gender stereotypes (Baudino, 2001), which makes the aforementioned mental representation less likely to be truly open. Previous research has indeed shown that stereotypes are very prominent in the construction of a mental representation of gender during reading (e.g., Carreiras, Garnham, Oakhill, \& Cain, 1996; Garnham, Oakhill, \& Reynolds, 2002).

Gygax et al. (2008) investigated the interaction between stereotypical information and grammatical gender in the representation of gender in French, German and English, the latter being their "control language", as none of the role names used were marked for gender. To 
appropriately capture stereotypical information, they chose role names from a questionnaire study by Gabriel, Gygax, Sarrasin, Garnham, and Oakhill (2008), which produced norms for the gender stereotypicality of 126 role names in three languages (i.e., English, French, German).

From this questionnaire study, Gygax et al. (2008) chose twelve female stereotyped role names, twelve male stereotyped role names and twelve neutral role names. These role names, also used in subsequent research, are shown in Table 1. In the experiment, based on the paradigm used by Garnham, Oakhill, and Reynolds (2002), the participants had to read pairs of sentences, one sentence after the other. In each pair, the first sentence included a role name as subject (e.g., The spies came out of the meeting room), and the second sentence contained explicit information about the characters' gender (e.g., It was obvious that one of the women was really angry). Participants had to decide whether the second sentence was a sensible, i.e., possible, continuation of the first one. The sentences were identical in the three languages, but in German and French the role names were in the masculine form, hypothetically interpretable as a generic.

Table 1

Role names chosen from Gabriel et al. (2008) and used in subsequent experiments along with the proportion of men evaluated by each language participant group

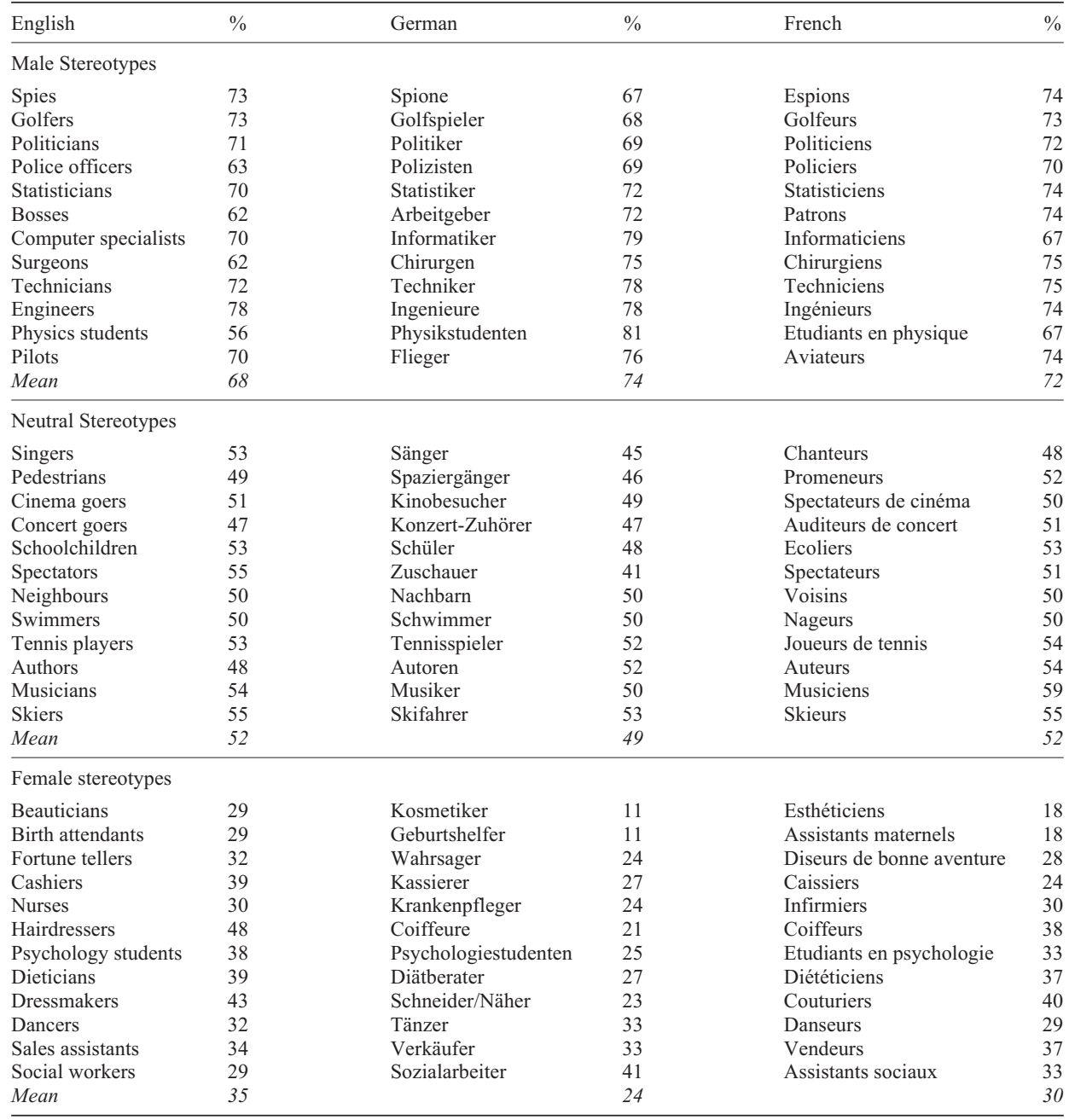


The results showed that in English, participants' gender representations of the role names were in line with the role names' stereotypicality, that is, participants responded yes more often when the role name's stereotypicality matched the gender of the character in the second sentence. When the role names were neutral, participants responded yes equally often to male and female characters. In French and German, however, the representations were equally male biased across all stereotypicality conditions. Participants responded yes more often when the character was a man, independently of the role name's stereotypicality. These results document that, in gender-marked languages such as French and German, university students do not readily apply the rule that the masculine can be considered as a non-specific, or generic, gender marker. As such, the influence of the masculine, as a specific mark, not only overrules stereotypical information, but also the generic interpretation.

\section{Solutions and disputes}

To overcome the seemingly difficult task of integrating and activating the grammatical rule of the generic interpretation of the masculine, several options have been suggested. In Norway, for example, the feminine gender marking has disappeared throughout the last thirty years (Swan, 1992) due to a language policy of gender-neutralisation that resulted in the previous masculine form being used as a common gender class (see also: the generic strategy, Hellinger, 1984). With reference to role names, Norwegian hence lies somewhere between semantic gender languages, such as English, which lack formal gender markings, and languages with a formal gender system, such as French, Italian or German, since in Norwegian there is only one form used to refer to human agents. Gabriel and Gygax (2008) investigated the effect of such a policy by replicating Gygax et al.'s (2008) experiment in Norwegian. The results showed that, although the Norwegian students did respond according to stereotypicality when presented with female and male stereotyped role names, their responses were male biased when presented with neutral stereotyped role names. This suggests that the specificity of the masculine form was only overruled when the role name strongly implied a stereotype. Gabriel and Gygax (2008) concluded that the gender representations in Norwegian seemed "to be overshadowed by a male bias that could be called the 'aftertaste' of the historical gendermarking of nouns" (p. 18). This is especially interesting, as the participants of this study were all born after the implementation of the new language policy. Essentially, the Norwegian change in language policy has not yet resulted in the desired full suppression of the male bias induced by the masculine form (see also Gabriel, 2008).

In other languages, different alternatives to the masculine-only form have been suggested. In English, for example, in which most nouns can be used either for men or women, many of the small number of gender marked nouns have been replaced (e.g., firefighter instead of fireman, postal worker instead of postman), or used in parallel with feminized terms (e.g., firewoman, postwoman) (The American Heritage Book of English Usage, 1996). In addition, the pronoun "he" used in a generic meaning has often been replaced by "they" or by splitting forms (e.g., he or she), at least in British English. In German, role names initially written only in the masculine form (e.g., Verkäufer, sales assistant) can be replaced by forms including women (e.g., Verkäuferinnen und Verkäufer, VerkäuferInnen Verkäufer/innen), or by nouns made from the present participles or from adjectives (e.g., die Verkaufenden) (Albrecht, 2000). Though in French nouns from participles or adjectives already exist and are gender marked, similar inclusive solutions exist (e.g., vendeuses et vendeurs, vendeurs/euses).

Unfortunately, although all of the alternative forms have been directed toward a suppression of the male bias introduced by the masculine-only form, they have faced various forms of opposition and have not encountered general and unconditional approval (Parks \& Roberton, 1998). In Switzerland, for example, the Federal Council has taken several measures since 1986 but has (surprisingly) considered the four official languages differently (Chancellerie Fédérale Suisse, 1993). Although legal documents in German are to be written using those alternatives, 
documents in French can be written using neutral or masculine-only forms. This policy might be an artefact of the traditions and recommendations of the Académie Française, responsible for all regulations on the usage of the French language, which in 2002 for example explicitly stated that writing role names in both masculine and feminine forms was "useless" and was disruptive to normal reading. The studies presented so far in this paper have, implicitly or explicitly, responded to the Académie Française's first argument, and Gygax and Gesto (2007) replied to the Académie Française's second one, and those embracing their ideas. They showed that although the first encounter of alternative terms to the masculine-only in a text did indeed slow down reading (i.e., which they considered as a sign of hindering), there was a very fast habituation effect, leading to a perfectly normal reading pace. Gygax and Gesto (2007) showed five texts to participants, each describing an occupation (e.g., mechanic), and each comprising three mentions of the occupation. Some participants saw the texts in the masculine-only form, whereas others read the text comprising alternatives to the masculine-only form (i.e., mécanicien-ne-s or mécaniciens et mécaniciennes). Gygax and Gesto (2007) monitored self-paced reading times and noticed that for the texts containing the alternative forms, although reading was slowed down by the first encounter of the occupation (taking sentence length into account), participants achieved a normal reading speed at the second and third encounter of the occupation. Gygax and Gesto (2007) argued that people get used to alternatives forms, which therefore only temporarily hinder reading.

The arguments of the Académie Française, which are often raised in France and the Frenchspeaking part of Switzerland, have several consequences, one of which is that there are no clear guidelines or rules for using gender-fair language in job advertisements in newspapers. Some employers may present job advertisements using the masculine-only form, and others may use alternative forms. Those using the masculine-only form may not do it to explicitly exclude women (i.e., some may still believe in the generic nature of the masculine). However, because alternative forms sometimes also appear, even if it is in other job descriptions, or on another page of the newspaper, Gygax and Gabriel (2008) argued that a generic interpretation of the masculine becomes even less likely. These researchers tested the idea that in a text in which some role names are presented in the masculine form and some in the feminine form, occurrences of role names written in the feminine form may make masculine role names less likely to be interpreted as generic. In other words, employing feminine forms (i.e., as in the alternatives to the masculineonly) encourages readers to interpret the masculine form as specific. In their first experiment, which is of interest here, participants were presented with pairs of words, each pair comprising a role name in the masculine plural form, and a noun in the singular form, which unambiguously represented either a man or a women (e.g., father, mother). Participants had to decide whether the person represented by the noun could be part of the group represented by the role name. For example, participants had to decide whether une mère [a mother] could be part of a group of infirmiers [nurses]. In the first experiment, which was divided into two parts, participants were first presented with role names written only in the masculine form (e.g., infirmiers). In the second part of the experiment, participants were presented with role names sometimes in the masculine form, sometimes in the feminine form (e.g., infirmières). The results showed an expected general male bias (i.e., participants were more likely to respond positively when the noun represented a man), but in the second part, in which some role names appeared in the feminine form, this bias was stronger than in the first part: Participants were even less likely to respond positively when a woman character was paired with a role name written in the masculine form. Note that this was completely independent of the stereotypicality of the role names presented to the participants. Gygax and Gabriel (2008) concluded that the mere appearance of role names in the feminine form induce a more strongly male biased mental representation of gender than the one found in previous experiments.

\section{Concluding comments}

To summarize, the work presented so far has shown two things. First, when there is no grammatical mark of gender, readers base their mental representation of gender on stereotype 
information. Second, the masculine form in gender-marked languages most often stimulates a male biased mental representation, even if readers have learnt that the masculine form may be considered as generic, and even when language policies attempt to accentuate its generic interpretation.

In most of the studies presented in this paper, university students' representation of gender was investigated. Although these students have spent a significant amount of time in education and hence should be highly familiar with the generic interpretation of the masculine, they did not usually produce generic interpretations. We believe that at least two main explanations could be advanced for this fact: one based on the cognitive difficulties of learning that one grammatical rule can override another one, and a second based on a bidirectional influence between grammar and stereotyping. Both explanations need to be considered in educational terms.

The first explanation relates to the sequence of acquisition of (a) the concept of masculine and feminine forms, and (b) the concept of a generic interpretation of the masculine. Acquiring the principle of grammatical gender is by no means an easy task, especially as, in French for example, the grammatical gender of nouns referring to inanimate beings is arbitrarily defined. Obviously, applying grammatical gender to animate beings is made easier by the analogy parallelism between grammatical and semantic gender. Unfortunately, this seemingly profitable analogy makes the generic interpretation of the masculine even more difficult to learn, let alone to apply. In a sense, one learns a rule to apply grammatical gender, and then encounters a different rule, essentially inhibiting the first one. Even if the rule is understandable, it may well be difficult to apply. Hyde (1984), who investigated pronominal grammatical gender in English, did indeed show that even when the rule had been learned and understood, it was not necessarily applied. Although our studies focused on languages that can be considered as true gender-marked languages (i.e., as opposed to English), we believe that our work gives strong support to Hyde's (1984) conclusions. Following this argument, it may well be difficult to learn and successfully apply the particular rule of the generic interpretation of the masculine, especially if its acquisition follows the one of grammatical gender.

The other explanation focuses on the complex interaction between stereotype and grammar. The example given in the introduction of this paper taken from the official handbook for 2 nd year primary school children in the French-speaking part of Switzerland is symptomatic. When learning about grammatical gender and animate beings children are given the examples of l'actrice [the actress] for the feminine form and le directeur [the director] for the masculine form. Not only do these role names exemplify the analogy between grammatical and semantic gender, but they also convey important stereotypical information. There is no doubt that children are exposed to a significant number of occurrences in which role names, or occupational titles are described, often in the masculine form (i.e., maybe even intended as generic). Repetitive exposition to these role names may anchor children's representations of a particular occupation as being male dominated. When learning the rule that occupations can be applied to both men and women, even when the masculine is used, children's stereotypical representation may not be flexible enough. Liben et al. (2002) showed that those children holding strong gender stereotypes are "likely to reinterpret non-traditional instances to make them consistent with their own beliefs" (p. 826).

To summarize, the grammatical rule stating that the masculine form can be interpreted as a generic form seems very difficult to apply, at least in gender marked languages such as French and German. The ambiguity regarding the interpretation of the masculine form seems to be inevitably resolved by interpreting it as a specific form (i.e., referring to men). This is true for younger readers, but also for university students. As no true regulations regarding the use of the masculine-only form in gender-marked languages are implemented in a consistent manner, we are faced with a mixture of masculine-only and parallel alternatives. This mixture increases the likelihood that the masculine form will be interpreted as a specific form, even when not intended as such (Gygax \& Gabriel, 2008; Liben et al., 2002).

To conclude, in terms of the practical implications of these processes, two related but different issues need to be emphasised. First, the use of the masculine form to describe role names to children may well provide them with an incorrect representation of society. Children 
may form a representation in which men are more active in society. Second, when reaching an age at which they begin to think about professional prospects, children's or adolescents' choices, more specifically young women's, will be biased towards thinking that few jobs are suited to women. Of course, these choices may also inevitably be influenced by stereotypical information. Therefore, although changes in the masculine bias induced by grammatical features may be implemented through language measures, such as the constant use of both masculine and feminine forms to describe groups of people, attitude changes, independent of language, are also needed.

\section{Notes}

1 These examples come from the Livre du maître; 2P. Office Romand des editions scolaires 1986 [Teacher's guide: 2nd level. Swiss French Educational Editions 1986], which is presently used in the French-speaking part of Switzerland.

2 Note that the generic nature of pronouns is usually introduced a little earlier, whether it is done formally or informally. Children can hence be exposed to the generic nature of the masculine earlier than planned by the official curriculum.

3 The authors raised the concern that writing job descriptions in gender-fair language may result in job depreciation. Role names written in the feminine form may activate the traditional representation of women, which carries a pejorative connotation (Chatard et al., 2005, p. 267). Jobs could thus be seen as devalued, leading participants to think that they are easier to obtain. To counter such an argument, they suggested that it was unlikely that highly valued jobs, such as doctor could suffer from such a depreciation. Gygax and Gesto (2007) empirically put this idea to the test and found no difference in the status evaluation of a job depending whether it was presented using only the masculine form or some alternative forms.

\section{References}

Albrecht, U. (2000). Unserer Sprache ist verbildet durch einen Maskulinismus. Die deutsche Schweiz auf dem Weg zu einer geschlechtergerechten Sprache [German Switzerland on the way to a gender-adequate language]. Bulletin Suisse de Psychologie Appliquée, 72, 11-46.

Académie Française. (2002). Féminisation des noms de métiers, fonctions, grades et titres. [Feminization of job tiles, posts, tanks and qualifications]. Retrieved May 24, 2005, from http://www.academie-francaise.fr/actualites/ feminisation.asp

Baudino, C. (2001). Politique de la langue et différence sexuelle: La politisation du genre des noms de métiers [Language politics and sexual difference:The politicization of job titles' gender]. Paris: L'Harmattan.

Braun, F. (1996). Das grosse I und seine Schwestern - eine kritische Bewertung [The capital I and its sisters - A critical evaluation]. Deutschunterricht, 48, 54-62.

Bussmann, H. (1995). Das Genus, die Grammatik und - der Mensch: Geschlechterdifferenz in der Sprachwissenschaft [Gender differences in linguistics]. In H. Bussmann \& R. Hof (Eds.), Genus. Zur Geschlechterdifferenz in den Kulturwissenschaften (pp. 114-160). Stuttgart: Körner.

Carreiras, M., Garnham, A., Oakhill, J., \& Cain, K. (1996). The use of stereotypical gender information in constructing a mental model: Evidence from English and Spanish. Quarterly Journal of Experimental Psychology Section A-Human Experimental Psychology, 49, 639-663.

Chancellerie Fédérale Suisse. (1993). Formulation non sexiste: Circulaire de la Chancellerie Fédérale du 19 août 1993 [Nonsexist language: Form of the Federal Chancellery, on the 19th of August 1993]. Berne: Services Linguistiques Centraux.

Chatard, A., Guimond, S., \& Martinot. D. (2005). Impact de la féminisation lexicale des professions sur l'auto-efficacité des élèves: Une remise en cause de l'universalisme masculin? [Occupational self-efficacy as a function of grammatical gender in French]. L'Année Psychologique, 105, 249-272.

Colé, P., \& Segui, J. (1994). Grammatical incongruence and vocabulary types. Memory \& Cognition, 22, 387-394.

Flaherty, M. (2001). How a language gender system creeps into perception. Journal of Cross-Cultural Psychology, 32, 18-31.

Gabriel, U. (2008). Language policies and in-group favouritism: The malleability of the interpretation of generically intended masculine forms. Social Psychology, 39, 103-107. 
Gabriel, U., \& Gygax, P. (2008). Do language amendments really change gender representations? The case of Norwegian. Scandinavian Journal of Psychology, 49, 451-457.

Gabriel, U., Gygax, P., Sarrasin, O., Garnham, A,. \& Oakhill, J. (2008). Au-pairs are rarely male: Role names' gender stereotype information across three languages. Behavior Research Methods, 40, 206-212.

Garnham, A., Oakhill, J., \& Reynolds, D. (2002). Are inferences from stereotyped role names to characters' gender made elaboratively? Memory \& Cognition, 30, 439-446.

Grévisse, M., \& Goose, A. (1993). Le bon usage: Grammaire Française [The correct usage: French grammar]. Paris: Duculot.

Guion, J., \& Guion, J. (2000). Orth: Apprendre l'orthographe [Orth: learning to spell]. Hatier: Paris.

Gygax, P., \& Gabriel, U. (2008). Can a group of musicians be composed of women? Generic interpretation of French masculine role names in absence and presence of feminine forms. Swiss Journal of Psychology, 67, 141-153.

Gygax, P., \& Gesto, N. (2007). Lourdeur de texte et feminisation [Féminisation of language and hindering reading]. L'Année Psychologique, 107, 233-250.

Gygax, P., Gabriel, U., Sarrasin, O., Garnham, A., \& Oakhill, J. (2008). There is no generic masculine in French and German: When beauticians, musicians and mechanics are all men. Language and Cognitive Processes, 23, 464-485.

Hellinger, M. (1984). Effecting social change through group action. Femine occupational titles in transition. In C. Kramarae, M. Schulz, \& W. O’Barr (Eds.), Language and power (pp. 13-153). London: Sage.

Hyde, J.S. (1984). Children's understanding of sexist language. Developmental Psychology, 20(4), 697-706.

Liben, L.S., Bigler, R.S., \& Krogh, H.R. (2002). Language at work: Children's gendered interpretations of occupational titles. Child Development, 73(3), 810-828.

Parks, J.B., \& Roberton, M.A. (1998). Contemporary arguments against non-sexist language: Blaubergs (1980) revisited. Sex Roles, 39, 445-461.

Peyer, A., \& Wyss, E.L. (1998). “JazzmusikerInnen - weder Asketen noch Müesli-Fifis”. Feministische Sprachkritik in der Schweiz, ein Überblick [“Jazz-musicians - neither ascetics nor cereals-picker". Feministic language critic in Switzerland, a review]. Germanistische Linguistik, 139-140, 117-154.

Stahlberg, D., Braun, F., Irmen, L., \& Sczesny, S. (2007). Representation of the sexes in language. In K. Fiedler (Ed.), Social communication (pp. 163-187). New York: Psychology Press.

Swan, T. (1992). All about Eve: Women in Norwegian newspapers in the 20th century. Working Papers on Language, Gender and Sexism, 37-54.

The American Heritage Book of English Usage. (1996). Boston: Houghton Mifflin.

Dans cet article, nous présentons l'idée que l'utilisation générique du masculin représente une règle grammaticale facile à apprendre mais difficile à appliquer lors de la compréhension de textes. Cette idée est soutenue, entre autres, par les travaux effectués par le groupe GREL (Gender Representation in Language) sur l'interaction entre les informations stéréotypées et grammaticales lors de l'élaboration d'une représentation mentale du genre lors de la lecture de noms de rôle. Les études présentées dans cet article montrent que la forme masculine utilisée comme une forme générique pour se référer à des personnes des deux sexes, ou des personnes dont le sexe n'est pas connu ou non pertinent, est vraisemblablement associée à son sens /spécifique/ dans les langues à marques grammaticales de genre (càd., la forme masculine se réfère laux/ /hommes/). Ceci est vrai alors que la nature /générique/ du masculin est une règle grammaticale usuelle apprise à l'école. La règle peut être apprise et comprise, mais est vraisemblablement difficile à appliquer.

Key words: Gender representation, Gender stereotypes, Generic masculine, Grammar, Language. 
Received: February 2008

Revision received: October 2008

Pascal Gygax. Département de Psychologie, Université de Fribourg, Rue Faucigny 2, 1700 Fribourg, Switzerland. E-mail: Pascal.Gygax@unifr.ch; Web site: //blog.unifr.ch/ppsa/

Current theme of research:

Text comprehension. Mental models. Cognitive psychology. Experimental psycholinguistics. Gender studies. Social cognition.

Most relevant publications in the field of Psychology of Education:

Gabriel, U., \& Gygax, P. (2008). Can language amendments change gender representation? The case of Norway. Scandinavian Journal of Psychology, 49(5), 451-457.

Gygax, P., \& Gabriel, U. (2008). Can a group of musicians be composed of women? Generic interpretation of French masculine role names in absence and presence of feminine forms. Swiss Journal of Psychology, 67, 141-153.

Gygax, P., Gabriel, U., Sarrasin, O., Garnham, A., \& Oakhill, J. (2008). There is no generic masculine in French and German: When beauticians, musicians and mechanics are all men. Language and Cognitive Processes, 23, 464-485.

Gygax, P., \& Gesto, N. (2007). Lourdeur de texte et feminisation [Féminisation of language and hindering reading]. L'Année Psychologique, 107, 233-250.

Gnesa, R., \& Gygax, P. (2005). Pertinence des messages de santé: Une étude sur les temps de lecture des phrases à messages préventifs [The pertinence of health messages: A study on reading times of sentences containing prevention health messages]. Bulletin de Psychologie, 58, 233-239.

Ute Gabriel. Department of Psychology, Norwegian University of Science and Technology, Dragvoll, NO-7491 Trondheim, Norway. E-mail: Ute.gabriel@svt.ntnu.no; Web site: www.ntnu.no/psykologi/english

Current theme of research:

Gender representation in Language. Stereotypes and prejudices. Reactions to deviant behavior.

Most relevant publications in the field of Psychology of Education:

Gabriel, U., \& Greve, W. (2003). The psychology of fear of crime. Conceptual and methodological perspectives. British Journal of Criminology, 43, 594-608.

Gabriel, U., Banse, R., \& Hug, F. (2007). The prediction of helping behaviour by implicit attitudes and the motivation to control prejudiced reactions. British Journal of Social Psychology, 46(2), 363-382.

Gabriel, U., Greve, W., \& Killias, M. (2006). Perspectives on aggression - Trends and agendas for psychological research (Editorial for Special Issue on Aggression). Swiss Journal of Psychology 65(2), 77-79.

Soellner, R., \& Gabriel, U. (2008). Typisch Kiffer? Stereotype und Personenwahrnehmung. [Typical pothead? Stereotypes and person perception]. SUCHT. Zeitschrift für Wissenschaft und Praxis, 54(1), 32-37.

Oriane Sarrasin. Research Unit Methodology, Inequality, and Social Change, Faculty of Social and Political Sciences, University of Lausanne, Bâtiment Vidy, CH-1015 Lausanne, Switzerland. E-mail: oriane.sarrasin@unil.ch

Current theme of research:

Attitudes. Sexism. Cultural diversity.

Most relevant publications in the field of Psychology of Education:

Gygax, P., Gabriel, U., Sarrasin, O., Garnham, A., \& Oakhill, J. (2008). There is no generic masculine in French and German: When beauticians, musicians and mechanics are all men. Language and Cognitive Processes, 23, 464485 . 
Jane Oakhill. Department of Psychology, Unversity of Sussex, Dept. of Psychology, Life Sciences, University of Sussex, Brighton, BN19QH, United Kingdom. E-mail: j.oakhill@sussex.ac.uk; Web site: www.sussex.ac.uk

Current theme of research:

Mental models of text comprehension. Children's reading comprehension: Development and difficulties. Stereotype inferences in adults' text comprehension.

Most relevant publications in the field of Psychology of Education:

Brandao, A.C.P., \& Oakhill, J.V. (2005). "How do you know this answer?" - Children's use of text data and general knowledge in story comprehension. Reading and Writing, 18, 687-713.

Cain, K., \& Oakhill, J.V. (2006). Assessment matters: Issues in the measurement of reading comprehension. British Journal of Educational Psychology,76(4), 697-708.

Oakhill, J.V., \& Petrides, A. (2007). Sex differences in the effects of interest on boys' and girls' reading comprehension. British Journal of Psychology, 98, 223-235.

Oakhill, J.V, Cain, K., \& Bryant, P.E. (2003) Dissociation of single-word reading and text comprehension skills. Language and Cognitive Processes, 18(4), 443-468.

Weekes B.S, Hamilton S., Oakhill J.V., \& Holliday R.E. (2008). False recollection in children with reading comprehension difficulties. Cognition, 106, 222-233.

Alan Garnham. Department of Psychology, University of Sussex, Department of Psychology, University of Sussex, Brighton, BN1 9QH, United Kingdom. E-mail: A.Garnham@sussex.ac.uk; Web site: www.sussex.ac.uk

Current theme of research:

Text comprehension. Mental models.

Most relevant publications in the field of Psychology of Education:

Gygax, P., Gabriel, U., Sarrasin, O., Oakhill, J.V., \& Garnham, A. (2008). Generically intended, but specifically interpreted: When beauticians, musicians and mechanics are all men. Language and Cognitive Processes, 23, 464-485.

Oakhill, J.V., Garnham, A., \& Reynolds, D.J. (2005). Immediate activation of stereotypical gender information in reading. Memory \& Cognition, 33, 972-983.

Perner, J., Brandl, J.L., \& Garnham, A. (2003). What is a perspective problem? Developmental issues in belief ascription and dual identity. Facta Philosophica, 5, 355-378.

Perner, J., Rendl, B., \& Garnham, A. (2007). Objects of desire, thought, and reality: Problems of anchoring discourse referents in development. Mind and Language, 22, 475-513.

Reynolds, D.J., Garnham, A., \& Oakhill, J.V. (2006). Evidence of immediate activation of gender information from a social role name. Quarterly Journal of Experimental Psychology, 59, 886-903. 